\title{
Unilateral Frosted Branch Angiitis in An Immunocompromised Patient With Concurrent Coronavirus Disease 2019 Infection
}

TSU HONG LIM ( $\nabla$ naohiro_lim@hotmail.com )

Hospital Queen Elizabeth

\section{Yong Zheng WAI}

Hospital Queen Elizabeth

Jia Cherng CHONG

Hospital Queen Elizabeth

\section{Brief report}

Keywords: Frosted branch angiitis, Coronavirus disease 2019, Cytomegalovirus

Posted Date: January 13th, 2021

DOl: https://doi.org/10.21203/rs.3.rs-143416/v1

License: (c) (1) This work is licensed under a Creative Commons Attribution 4.0 International License.

Read Full License 


\section{Abstract}

Background Frosted branch angiitis is an uncommon ocular sign with multiple causes. With the advent of coronavirus disease 2019 (COVID-19) pandemic, more and more cases of ocular manifestation with COVID-19 has been reported. These poses great challenges to clinicians when handling COVID-19 patients with ocular signs and symptoms. The challenges are even greater when dealing with uncommon disease that co-exists with COVID-19 as both diseases are not well understood. Finding We report the first case of frosted branch angiitis in a patient with coexisting cytomegalovirus and COVID-19 infection. A 33year-old gentleman with underlying acquired immunodeficiency syndrome who was newly started on highly active antiretroviral therapy, complained of gradual blurring of vision one month after he was diagnosed positive for COVID-19. Upon clinical examination, fundus findings demonstrated extensive perivascular sheathing of both artery and vein, suggestive of frosted branch angiitis of the right eye. Laboratory investigations revealed both nasal swab for COVID-19 polymerase chain reaction and serum cytomegalovirus antibody was positive. The patient was then admitted to COVID-19 ward and treated with intravenous ganciclovir. Conclusion The challenges remain when handling Covid-19 patients with FBA. However, clinicians need to be aware of the possible coexistence of COVID-19 in an immunocompromised patient with frosted branch angiitis.

\section{Introduction}

Frosted branch angiitis (FBA) is an uncommon condition characterized by extensive translucent retinal perivascular sheathing involving both arterioles and venules. It has been associated with several conditions, most commonly in immunocompromised individuals with cytomegalovirus (CMV) infection (1). To our best knowledge, there are no reported cases of FBA in a patient of coinfection with CMV and coronavirus disease 2019 (COVID-19) up to date.

We hereby report the first case of FBA in a patient with coexisting CMV and COVID-19 infection.

\section{Case Report}

A 33-year-old man was newly diagnosed with AIDS in September 2020. His other infective screening such as hepatitis $B$, hepatitis $C$, toxoplasma, syphilis, cryptococcal, and tuberculosis were unremarkable. CD4+ T lymphocyte count taken on September 2020 was noted to be 9 cells $/ \mathrm{mm}^{3}$. He was subsequently started on Highly Active Antiretroviral Therapy (HAART) the following month. A month later he had contact with a COVID-19 positive person and a nasal swab for COVID-19 polymerase chain reaction was done. The result turned out that he was positive for COVID-19.

He was presented to us in December 2020 complaining of progressive blurring of vision on his right eye for the past 2 months. His visual acuity over the right eye was $6 / 60$ and $6 / 7.5$ over the left eye. No significant abnormalities were noted upon examination of the bilateral eye anterior segment. Generalized retinal vasculitis with severe sheathing of the retinal vessels and mild vitritis was seen over the right eye 
on fundus examination (figure 1). Frosted branch angiitis was noted. No abnormalities were found over the left eye fundus examination. Subsequently, serum serology for CMV was taken and found to be positive for both IgM and IgG. At that point of time, his nasal swab for COVID-19 was still positive with a low cycle threshold value.

The patient was then admitted into COVID-19 ward for 2 weeks. He was treated with intravenous (IV) ganciclovir $5 \mathrm{mg} / \mathrm{kg}$ for two weeks. His repeated CD4+ T lymphocyte count upon admission increased to $41 \mathrm{cells} / \mathrm{mm}^{3}$. The patient was seen back in the clinic one week after the completion of his IV ganciclovir. It was noted that his frosted branch angiitis over his right eye has improved gradually and his best corrected visual acuity recovered to $6 / 12$.

\section{Discussion}

The word FBA was first described by lto et al. back in the year 1976 when they found a thick perivascular sheathing in a 6-year-old boy's fundus. (2)

There are many conditions associated with FBA, some of which include Behcet's disease, SLE, CMV retinitis, Crohn's disease, mycobacterium tuberculosis infection, aseptic meningitis, leukemia, lymphoma, herpes simplex type 2, varicella-zoster virus, and several other bacterial and viral infections.(1,3,12,4-11) FBA is more commonly bilateral, however unilateral presentation has previously been reported (13).

The World Health Organisation declared an international state of emergency for novel COVID-19 on $5^{\text {th }}$ April 2020. Ocular manifestation in a patient infected with COVID-19 is still not well established. It is suspected that viral transmission can occur through the eye and patients can present with conjunctivitis, keratoconjunctivitis, and epiphora as early symptoms of COVID-19 infection (14). The top three COVID-19 related ocular symptoms are dry eye, blurring of vision, and foreign body sensation(15).

To our best knowledge, we have only found one case reporting co-infection of COVID-19 and cytomegalovirus, but it did not state any eye findings(16). There are no reported cases of FBA in an immunocompromised patient with concurrent coronavirus disease 2019 infection up to date which causes us the dilemma of the cause of this patient's FBA. A recent article reported by Le Balc'h et al.(17) states that frequent reactivation of cytomegalovirus was detected among patients diagnosed with COVID-19, with no ocular involvement mentioned in the study. Although serum cytomegalovirus serology for this patient was positive, we should not rule out the possibility of concurrent COVID-19 infection might have aggravated the occurrence of FBA in this case.

Another case reported in Spain showed a possible association of retinal vasculitis with COVID-19 in children with Chilblains (18). Although the case was reported in children and not in adults, it has shown that there might be some association between retinal vasculitis and COVID-19 towards the cause of FBA. 
The role of COVID-19 in ocular manifestation is still not well understood. This is the first reported case that describes the coexistence of FBA in an immunocompromised patient with COVID-19. Further research is needed to understand this condition better.

\section{Conclusion}

Amidst COVID-19 pandemic, ophthalmologists need to be more cautious when treating immunocompromised patients with FBA, as it might coexist with COVID-19.

\section{Abbreviations}

FBA: Frosted Branch Angiitis

AIDS: Acquired immunodeficiency syndriome

CMV: Cytomegalovirus

COVID-19: coronavirus disease 2019

HAART: Highly Active Antiretroviral Therapy

IV: Intravenous

\section{Declarations}

\section{Ethics approval and consent to participate:}

- Not applicable

\section{Consent for publication:}

- Consent obtained from patient

\section{Availability of data and materials}

- Not applicable

\section{Competing interests}

- The authors declare that they have no competing interests

\section{Funding}

- Not applicable

\section{Author's contributions}


- LIM TH, WAI YZ participated in the drafting of the manuscript.

- LIM TH participated in the management of the patient.

- WAI YZ contributed to the fundus photo construction.

- All authors read and approved the final manuscript.

\section{Acknowledgements}

- Not applicable

\section{References}

1. Spaide RF, Vitale AT, Toth IR, Oliver JM. Frosted branch angiitis associated with cytomegalovirus retinitis. Am J Ophthalmol [Internet]. 1992;113(5):522-8. Available from: http://dx.doi.org/10.1016/S0002-9394(14)74723-3

2. Ito Y. Frosted branch angiitis in a child. Rinsho Ganka (Jpn J Clin Ophthalmol). 1976;30:797-803.

3. Kwon SJ a., Park DH o., Shin JP i. Frosted branch angiitis as ocular manifestation of Behçet's disease: unusual case report and literature review. Korean J Ophthalmol. 2013;27(6):466-9.

4. Hernandez-Da Mota SE, Arellanes-Garcia L, Recillas-Gispert C, Cornejo-Ballesteros H, Melgoza-DelAngel C, Teran-Estrada L, et al. Lupus relapse presented as frosted branch retinal angiitis: Case report. Ocul Immunol Inflamm. 2011;19(5):367-9.

5. Sykes SO, Horton JC. Steroid-responsive retinal vasculitis with a frosted branch appearance in crohns disease. Vol. 17, Retina. 1997. p. 451-4.

6. Zhao H, Guan J, Zhou L, Zhang Q, Si Y. Frosted branch angiitis in a woman with mycobacterium tuberculosis infection. Ocul Immunol Inflamm. 2012;20(3):227-9.

7. Matsui Y, Tsukitome H, Uchiyama E, Wada Y, Yagi T, Matsubara H, et al. Peripheral capillary nonperfusion and full-field electroretinographic changes in eyes with frosted branch-like appearance retinal vasculitis. Clin Ophthalmol. 2013;7(1):137-40.

8. Kim TS, Duker JS, Hedges TR. Retinal angiopathy resembling unilateral frosted branch angiitis in a patient with relapsing acute lymphoblastic leukemia. Am J Ophthalmol. 1994;117(6):806-8.

9. Hua MT, Blaise P, De Leval L, Rakic JM. Frosted branch angiitis with undiagnosed Hodgkin lymphoma. Eur J Ophthalmol. 2009;19(2):310-3.

10. 1999 Retinal vasculitis with a frosted branch angiitis-like response due to herpes simplex virus type 2.pdf.

11. Talebi-Taher M, Javadzadeh A, Hedayatfar A, Rahmani S, Ghanooni AH, Mahmoodian R. Frosted branch angiitis caused by Varicella Zoster virus in an immunocompetent patient. Iran J Microbiol. 2015;7(2):118-22.

12. Walker S, Alguchi A, Jones NP. Frosted branch angiitis: A review. Eye. 2004;18(5):527-33. 
13. Sugin SL, Henderly DE, Friedman SM, Jampol LM, Doyle JW. Unilateral frosted branch angiitis. Am J Ophthalmol. 1991;111(6):682-5.

14. Nuzzi R, Carucci LL, Tripoli F. COVID-19 and ocular implications: an update. J Ophthalmic Inflamm Infect. 2020;10(1).

15. Chen L, Deng C, Chen X, Zhang X, Chen B, Yu H, et al. Ocular manifestations and clinical characteristics of 535 cases of COVID-19 in Wuhan, China: a cross-sectional study. Acta Ophthalmol. 2020;(81974136).

16. D'Ardes D, Boccatonda A, Schiavone C, Santilli F, Guagnano MT, Bucci M, et al. A Case of Coinfection with SARS-COV-2 and Cytomegalovirus in the Era of COVID-19. Eur J Case Reports Intern Med. 2020; (Vol 7 No 5):1.

17. Le Balc'h P, Pinceaux K, Pronier C, Seguin P, Tadié JM, Reizine F. Herpes simplex virus and cytomegalovirus reactivations among severe COVID-19 patients. Crit Care. 2020;24(1):1-3.

18. Quintana-Castanedo L, Feito-Rodríguez M, Fernández-Alcalde $C$, Granados-Fernández $M$, MonteroVega D, Mayor-Ibarguren A, et al. Concurrent chilblains and retinal vasculitis in a child with COVID-19. J Eur Acad Dermatology Venereol. 2020;

\section{Figures}




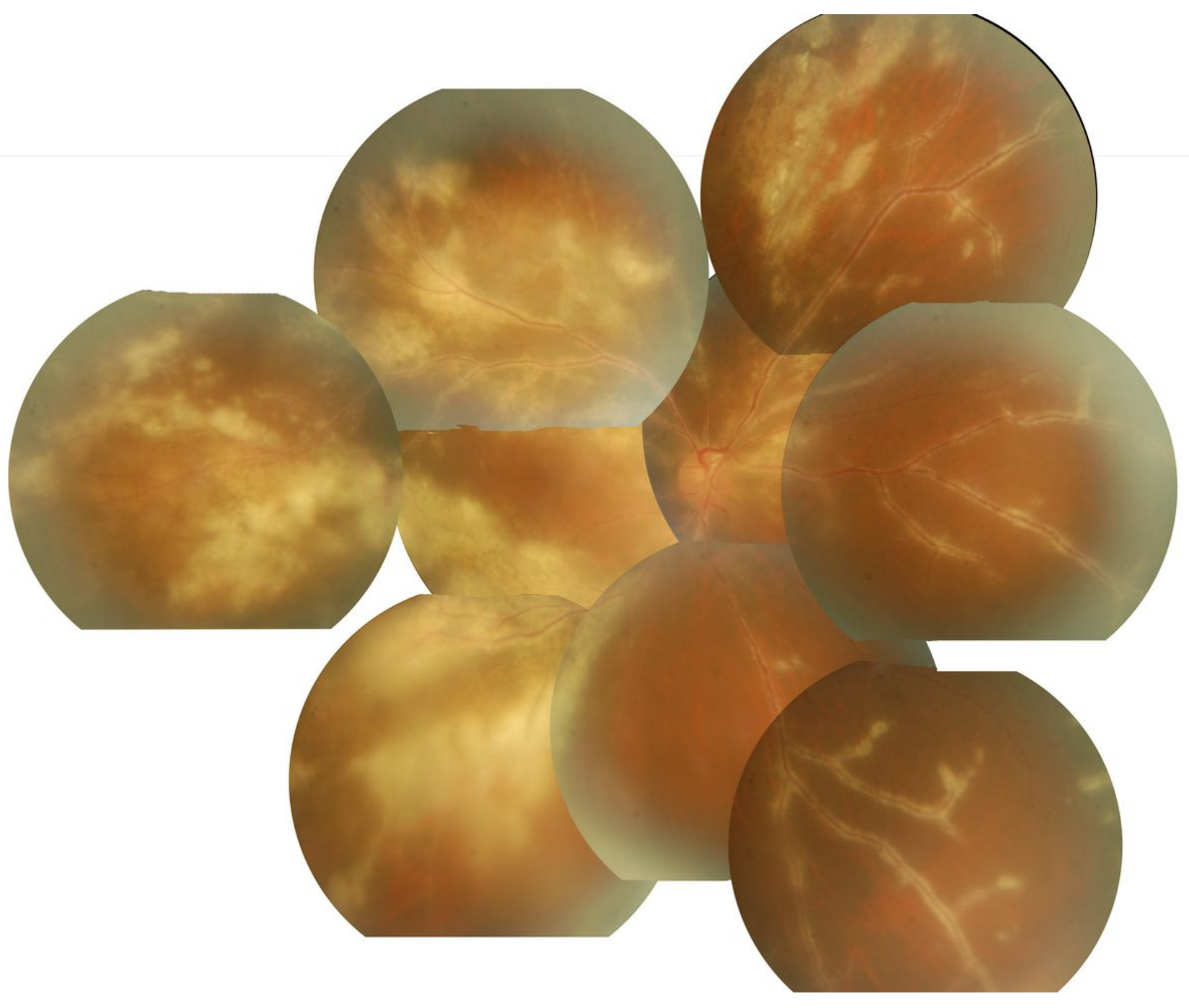

Figure 1

Perivascular sheathing of artery and vein suggestive of frosted branch angiitis of the right eye. 